\title{
A possível fonte da seta do tempo causal em explicações geo-históricas
}

\section{THE POSSIBLE SOURCE OF THE CAUSAL TIME ARROW IN GEO-HISTORICAL EXPLANATIONS}

\author{
Gadi Kravitz \\ Departamento de Filosofia, Universidade de Haifa, IsRael. \\ EMAIL: GADIKR@NETVISION.NET.LL, \\ Traduzido por: Fabrício de Andrade Caxito \\ Centro de Pesquisa Manoel Teixeira da Costa e Departamento de Geologia, Instituto de Geociências, Universidade Federal de Minas Gerais (CPMTC-IGC-UFMG), \\ Avenida Antonio Carlos 6627, Pampulha, 31260-440, Belo Horizonte, MG. \\ EMAIL: GADIKR@NETVISION.NET.IL, CAXITO@UfMg.BR \\ Publicação original: Kravitz, G. (2017). The possible source of the causal time arrow in ge0-historical explanations. Geoscience Frontiers, 8, 555-564. \\ DOI: 10.1016/J.GSF.2016.05.006
}

\begin{abstract}
My argument in this article, will be that nature, in general, and human nature in particular, suggests that, in principle, it is possible to derive the causal time arrow from several physical time arrows existing in nature and appearing to be unidirectional and irreversible phenomena. A more concrete argument will be that the assumption of a causal time arrow to which geologists resort in all geo-historical explanations, apparently originates in geo-historica time arrows concealed in unidirectional and irreversible physical-geological processes. I will illustrate this claim with a few examples of geo-historical explanations in the theory of plate tectonics, most of which are based on irreversible geo-physical processes. My final argument is a broader, of an epistemological nature, according to which the causal time arrow assumption used in logical-causative explanations in everyday life and in science, apparently "derives" in a way from the geo-historical time arrow. I will base this argument on the causal relationship and mutual influence that occurs in nature between geo-historical and evolutionary processes in animals, including developmental processes of the human brain and mind. From this reductionist argument, nicely integrated in the framework of evolutionary epistemology (EEM), it is possible to derive a wider naturalistic argument according to which, on principle, the laws of geo-historical physics can be reduced to the laws of logic and causality. (C2016, China University of Geosciences (Beijing) and Peking University. Production and hosting by Elsevier B.V. This is an open access article under the CC BY-NC-ND license (http://creativecommons.org/licenses/by-nc-nd/4.0/).
\end{abstract}

Resumo: Meu argumento neste artigo será que a natureza, em geral, e a natureza humana, em particular, sugere que, em princípio, é possível derivar a seta do tempo causal de diversas outras setas físicas do tempo na natureza que parecem ser fenômenos unidirecionais e irreversíveis. Um argumento mais concreto será que a suposição de uma seta do tempo causal a qual geólogos recorrem em todas as explicações geohistóricas aparentemente se origina de setas do tempo geohistóricas escondidas em processos físico-geológicos unidirecionais e irreversíveis. Eu irei ilustrar esta afirmação com alguns exemplos de explicações geohistóricas na teoria da Tectônica de Placas, a maioria das quais é baseada em processos geológicos e físicos irreversíveis. Meu argumento final é mais amplo, de natureza epistemológica, segundo o qual a suposição de uma seta do tempo causal utilizada em explicações lógico-causativas no dia a dia e na ciência aparentemente é "derivada" de certa forma da seta do tempo geohistórica. Eu irei basear este argumento na relação causal e na influência mútua que ocorre na natureza entre processos geohistóricos e evolutivos em animais, incluindo processos de desenvolvimento do cérebro e da mente humana. Deste argumento reducionista, bem integrado no quadro da Epistemologia Evolutiva, é possível derivar uma grande quantidade de argumentos naturalísticos de acordo com os quais, em princípio, as leis da física geohistórica podem ser reduzidas às leis da lógica e da causalidade.

\section{Introdução}

A questão "o que é o tempo"? têm preocupado muitos filósofos desde tempos imemoriais. Mesmo hoje, muitos são preocupados com esta questão, e, de fato, o quebra-cabeças do tempo continua não resolvido. Desta forma, ao invés de lidar com a
Citation/Citação: Kravitz, G. (2020). A possível fonte da seta do tempo causal em explicações geo-históricas. Trad. F. A. Caxito. Terræ Didatica, 16, 1-16, e020007. doi:10.20396/ td.v16i0.8658360.

Keywords: Evolutionary epistemology, Philosophy of geohistorical thinking.

Palavras-chave: Epistemologia evolutiva, Filosofia do pensamento geo-histórico.

\section{Manuscript/Manuscrito:}

Received/Recebido: 01/12/2017

Revised/Corrigido: 04/07/2019

Accepted/Aceito: 12/02/2020

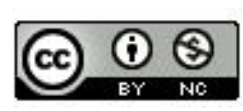

\begin{tabular}{c|c|c|c|c|c|}
\hline C Terrae Didat. & Campinas, SP & v.16 & $1-16$ & $\mathrm{e} 020007$ & 2020 \\
\hline
\end{tabular}

questão se o tempo realmente existe ou se é apenas uma invenção de nossos pensamentos, eu irei lidar principalmente com sua propriedade básica e senso comum, que diferencia entre passado e futuro - a propriedade assimétrica, ou na descrição metafórica, a seta do tempo - a seta unidirecional 
irreversível do tempo geohistórico, baseado principalmente nas leis da física e da geologia. Para atingir este objetivo, focar-me-ei a lógica atualista, na base das explicações geohistóricas que permitem aos geólogos reconstruir o passado geológico da Terra. Primeiramente, irei argumentar que esta lógica, entre outras coisas, é baseada no princípio metafísico fundamental de acordo com o qual a causa sempre precede o efeito no tempo. Além disso, esta afirmação pode ser baseada na seta do tempo geohistórica que empiricamente reflete processos geológicos e físicos temporalmente irreversíveis. Eu posso apoiar este argumento em muitos exemplos. Finalmente, eu argumentarei com uma relação causal no sentido biológico-físico entre a seta do tempo geohistórica e a seta do tempo biológica. $\mathrm{Na}$ última parte do artigo eu tentarei apresentar um argumento baseado na visão Darwiniana da natureza, que apoia o argumento central deste artigo, sobre a possibilidade de redução da seta do tempo geohistórica que é física em essência, à seta do tempo causal, que constitui a base sólida para qualquer explicação científica e não científica. Deste argumento reducionista, bem integrado no quadro da Epistemologia Evolutiva, nós podemos derivar um argumento naturalístico mais amplo, que afirma que, em princípio, é possível reduzir as leis geohistóricas da física às leis da lógica e da causalidade.

\section{A estrutura do argumento lógico-causal em explicações geohistóricas}

Um dos maiores desafios da ciência moderna que é baseada numa aproximação empírica é explicar o significado de alegações referentes ao passado. O processo de verificação baseado em traços do passado não é nada mais do que nossa interpretação. A aproximação atualista na geologia moderna ${ }^{1}$ supostamente resolve o problema ao afirmar que eventos geológicos passados na Terra têm efeitos presentes e futuros, e que este podem ser verificados diretamente pelo geólogo. O método atualista corrente assume que, com base em observações de fenômenos geológicos que ocorrem no presente, nós podemos reconstruir e explicar o passado geológico da Terra de uma forma analógica (ou com a ajuda de analogias). Neste sentido, o geohistoriador pensa para trás (em direção ao passado) e então, supostamente, artificialmente inverte a direção do tempo em processos geohistóricos que ocorrem na natureza. O que pode justificar o uso de explicações analógicas para reconstruir o passado geológico da Terra a partir de observações de eventos geológicos que ocorrem no presente e de traços deixados pelo passado geológico?

As inferências analógicas não são aplicáveis a conclusões que surgem de suposições baseadas em necessidades lógicas, mas são vistas como mais prováveis ou menos prováveis. Em explicações geohistóricas, uma alta probabilidade é atingida graças ao princípio de uniformidade ${ }^{2}$ assumido pelos geólogos, que esconde a generalização fundamental sobre a causalidade que afirma que as relações causais entre causa geológicas e efeitos não mudam significantemente com o passar do tempo, e, portanto, podemos assumir que as mesmas causas levam aos mesmos efeitos ${ }^{3}$. Especificamente, para produzir uma analogia entre duas entidades é preciso começar apontando um ou mais atributos e revelando a similaridade entre eles. Uma inferência analógica é baseada na similaridade entre duas ou mais coisas, e na projeção desta similaridade em algum outro aspecto destas coisas. Em outras palavras, uma analogia é produzida por meio da observação de características comuns entre certas coisas e a conclusão que outras características similares podem também ser encontradas nelas. Inferências indutivas tão simples acompanham nosso pensamento diário regularmente e sem elas não poderíamos sobreviver.

De uma maneira simples, o padrão dos argumentos (inferências) por analogia pode ser descrito como segue 4 :

Premissa A - A coisa A contém as características $1,2,3 \ldots$

Premissa B - A coisa B contém as características $1,2,3 \ldots$

Premissa C - É descoberto que a coisa A também contém a característica 7.

Conclusão - Logo, a coisa $\mathrm{B}$ também contém a característica 7.

Uma vez que na geologia lidamos, entre outras coisas, com processos e fenômenos geológicos que ocorreram há muito tempo atrás, as inferências analógicas desempenham um grande papel em nossa profissão, e o seu nível de complexidade excede mesmo o da maioria das ciências naturais ${ }^{5}$ que não se preocupam com o "tempo profundo". Em explicações geohistóricas, além da similaridade entre as características de fenômenos e eventos geológicos, os geólogos também procuram por similaridades entre leis causais que geralmente abrangem uma 
explicação para o mecanismo que opera no processo geológico. Neste sentido, eles assumem que o mecanismo causal que produz o fenômeno geológico não muda significantemente (o principio da uniformidade) e, portanto, a relação entre causa e efeito em dois fenômenos geológicos não muda com o tempo ${ }^{7}$. Tal lei causal permite ao atualista argumentar legitimamente que, com base na observação dos efeitos e processos no presente, o geólogo pode reconstruir o passado. Então, o atualismo assume que efeitos podem explicar ou provar causas da mesma forma que as causas podem explicar ou justificar os efeitos. Como esta afirmação pode ser justificada? Ou como podemos justificar que as causas se originaram dos efeitos? Como no paradoxo do "ovo e da galinha", existe certo tipo de circularidade - as causas explicam os efeitos e os efeitos explicam as causas ${ }^{8}$. Porém, devemos atentar que ao contrário das causas às quais os geólogos não tem quase nenhum acesso direto, os efeitos possuem certeza e isto explica sua importância em explicações geohistóricas. Tipicamente, geólogos são capazes de identificar efeitos no presente claramente, mas não tem acesso direto ao passado de forma que as causas permanecem especulativas. Geólogos tentam derivar as causas dos efeitos, porque empiricamente os efeitos são acessíveis e neste sentido eles são o que temos de mais certo. Isto é similar ao método cientifico apresentado por Descartes em seu famoso livro "Discurso do Método" (Kenaz, 2010, p. 40-50, 90-107), já que na ciência geológica, causas não podem provar os efeitos, mas apenas explica-los e clarifica-los. O papel das causas é explicar ou clarificar os efeitos e o papel dos efeitos é testar, validar, afirmar e confirmar as causas. Desta forma, para explicar as causas, os geólogos as assumem por um processo de seleção da melhor hipótese, que é por vezes chamado Inferência à Melhor Explicação'. Neste sentido, um não provado, logicamente inválido "salto" de hipóteses (causas) emana de fatos (efeitos). De fato um problema ou questão conhecido se levanta aqui ${ }^{10}$ : como podemos provar a hipótese que explica as observações somente baseado nos efeitos que são observações singulares? Na prática, para circundar a dificuldade e permitir que o trabalho geológico prático aconteça, os atualistas constroem o passado por meio da edificação de um sistema conceitual teórico (princípio da uniformidade) que liga fatos à causas ${ }^{11}$. Com o auxílio deste sistema conceitual e analogia relevantes ao caso, os geólogos procuram por uma característica ou circunstância que é relevante a outra porque tem um efeito causal nela. Neste sentido eles efetivamente constroem o passado geológico ao invés de encontra-lo, como pode ser compreendido por uma aproximação atualista ingênua ${ }^{12}$. Entretanto, deve ser notado que para avaliar argumentos analógicos, um conhecimento específico das relações causais é necessário e estas só podem ser reveladas pelas ferramentas empíricas - observação e experimento. Este conhecimento é percebido pelos geólogos como uma base cientifica solida sobre a qual, de fato, todas as explicações causais geohistóricas são baseadas. Explicações baseadas apenas em relações causais são cientificamente inadequadas para os geólogos para explicar os fatores (causas) de ocorrência dos fenômenos geológicos observados empiricamente no presente (efeitos). De toda forma, apesar da diferença entre implicações lógicas e causais ${ }^{13}$, os geólogos tendem a utilizar argumentos lógico-causais combinados ${ }^{14}$. Isto significa que argumentos lógicos são usados, mas que na verdade essas explicações são causais, baseadas em argumentos fatuais sobre o estado de coisas no que diz respeito ao estado geológico da Terra no passado e no presente, que demandam o teste de coisas no mundo ${ }^{15}$. Em outras palavras, os geólogos acreditam que existe uma correspondência injetável entre razões lógicas e implicações expressa por meio de criações epistemológicas linguísticas (frases e afirmações), e causas físicas que de fato ocorrem na natureza (entidades ontológicas), que alegam estar entre elas e dominar a natureza de implicações causais. Em um sentido, há uma transição não comprovada ("salto") até mesmo aqui, e desta forma a transição do nível epistemológico ao nível ontológico do mundo permanece em dúvida. As questões relevantes nesta conexão são: é possível justificar tal transição e, se sim, de qual forma? Os geólogos podem praticamente evitar tal transição, e se sim, como? Antes de tentar responder a estas questões, eu irei discutir brevemente algumas questões filosóficas, que emergem de um olhar sobre as formas logicas dos argumentos e explicações geohistóricas, assumindo que seu uso é justificado, pelo menos em um sentido prático. Na verdade, ao utilizar estes argumentos (explicações) os geólogos estão tentando preencher o requisito do empirismo na ciência moderna - a testabilidade.

Os geólogos tem quatro possíveis estruturas (padrões) de argumentos lógicos-causais à sua disposição para construir uma explicação geohistórica plausível, onde $\mathrm{C}$ indica causa e $\mathrm{E}$ indica efeito ${ }^{16}$. Em todos estes argumentos, as sentenças (1) e (2) são introduções (ou premissas) e a sentença (3) representa a conclusão do argumento. Os argumentos são como se segue:

\begin{tabular}{c|c|c|c|c|c}
\hline (C) Terrae Didat. & Campinas, SP & v.16 & $1-16$ & $\mathrm{e} 020007$ & 2020 \\
\hline
\end{tabular}


I.

(1) Se C ocorreu e então E ocorreu

(2) C ocorreu

(3) Logo, E ocorreu

II.

(1) Se C ocorreu e então E ocorreu

(2) C não ocorreu

(3) Logo, E não ocorreu

III.

(1) Se C ocorreu e então E ocorreu

(2) E ocorreu

(3) Logo, C ocorreu

IV.

(1) Se C ocorreu e então E ocorreu

(2) E não ocorreu

(3) Logo, C não ocorreu

Uma dificuldade fundamental é associada com a primeira premissa destes argumentos, que eu vejo como o principal tema no presente artigo. Como pode ser visto, em todas as inferências mencionadas acima, a primeira premissa é idêntica e constitui uma sentença condicional causal, da qual a primeira seção se refere à causa, e a seção final ao efeito. De um ponto de vista lógico formal, esta sentença afirma que se a primeira seção é real então a seção final também deve ser real, e descreve a relação entre a primeira e a última seção sem entrar na razão (conteúdo) e no significado da relação entre as duas partes da sentença. Porém, apesar de esta ser uma sentença condicional (implicação material) integral a todo o argumento lógico, e ao conteúdo e significado do conceito que contem, ela também diz respeito a relações causais entre a causa e o efeito, então a seção final não necessariamente é implicada logicamente, ou por definição, da sua primeira seção, mas é devido à relação causal entre elas (qualquer lei causal). Esta premissa, de fato, permite a um argumento causal ser apresentado como um argumento lógico. Apresentar um argumento lógico não envolve qualquer intenção de determinar algo sobre o estado do mundo. A única intenção é indicar uma implicação logica entre as suposições do argumento e sua conclusão. Neste caso, a primeira premissa serve como ligação entre implicações causais e lógicas, e por isto, tem grande importância em explicações geohistóricas. Esta premissa é, de fato, uma sentença complexa, em um sentido sintático, a partir de sentenças simples, uma das quais é a conclusão. É possível, então, transformar uma sentença complexa "se C ocorreu então E ocorreu" em uma inferência independente com a simples sentença " $\mathrm{C}$ ocorreu; então, E ocorreu"17. Esta sentença e este argumento são sintéticos (oposto a analítico), i.e. a sentença complexa não é um argumento lógico válido, mas estende o conhecimento. No predicado, ela diz o que não é considerado no conceito do sujeito, isto é, o predicado não está incluído no sujeito. Esta verdade é baseada não apenas na lei de não-contradição e depende não apenas do significado dos seus termos (ou suas definições) e na sua forma lógica. Ela transmite conhecimento expresso a posteriori em uma sentença sintética. Esta declaração é posterior e então deriva da experiência, e sua verdade é contingente ${ }^{18}$. Em outras palavras, sentenças casuais deste tipo são posteriores e sintéticas, são derivadas da experiência, e sua veracidade não depende apenas de sua forma lógica. Relações causais expressas por estas sentenças podem ser detectadas apenas empiricamente ou logicamente ${ }^{19}$, e são, de fato generalizações indutivas, "disfarçadas" de leis causais ${ }^{20}$, atrás das quais três suposições metafisicas clássicas sobre a causalidade estão escondidas: (a) qualquer efeito necessariamente tem uma causa (o princípio de causalidade) (b) causas idênticas necessariamente tem efeitos idênticos (uma afirmação atualística baseada no princípio da uniformidade da natureza e às vezes chamado de legalidade causal) (c) a causa sempre precede o efeito no tempo (a seta do tempo causal).

Em minha opinião a suposição (c) é a mais importante porque transforma a sentença condicional apontada acima em uma sentença histórica utilizada como uma lei abrangente (o modelo de lei abrangente de Hempel ${ }^{21}$ para qualquer explicação histórico-causal, sem a qual a explicação não é possível. Em outras palavras, sem esta premissa, uma explicação geohistórica não seria possível uma vez que lida com a mais importante característica histórica do tempo, a direção irreversível do passado para o futuro.

Quando o geólogo neste argumento assume que "se C ocorreu então E ocorreu", ele implicitamente assume que $\mathrm{E}$ pode ocorrer apenas depois que $\mathrm{C}$ tenha ocorrido. Em outras palavras, $\mathrm{C}$ sempre precede E no tempo. Apesar de ser uma suposição metafísica da causalidade em sentido clássico, como ela pode ser possivelmente justificada para "salvar" os argumentos lógico-causais? Por que muitos geólogos consideram esta suposição sem a qual uma explicação geohistórica é impossível? Qual é a origem disto? Como estamos lidando com argumentos e sentenças lógicas do ponto de vista estrutural e com argumentos causais do ponto de vista do conteúdo, eu afirmo que as respostas para estas 
questões obtêm sua validade empírica do mundo de fenômenos empíricos que nos cerca. Como a ciência da geologia é baseada em fenômenos físicos, ela deve justificar o uso destes argumentos e sentenças com base em leis físicas unidirecionais irreversíveis no tempo, sobre as quais as explicações geohistóricas são baseadas. A necessidade reside no fato que geólogos, como seres humanos, evoluíram no quadro destas leis no curso da evolução terrestre e do mundo animal. Para clarificar esta posição eu irei primeiro apresentar exemplos de explicações geohistóricas baseadas nas leis unidirecionais da física, irreversíveis no tempo e implicitamente baseadas na suposição (c) como descrita acima. Então eu irei tentar apresentar argumentos filosóficos que suportam esta posição, e nos permitam discutir sobre uma possível redução entre a seta física do tempo que ocorre na natureza e a seta causal expressa nas explicações geohistóricas e em qualquer tipo de pensamento histórico que lida com eventos do passado ${ }^{22}$.

\section{Processos naturais irreversíveis na Geologia e na Biologia e a relação entre eles}

\section{Processos geológicos unidirecionais, irreversíveis no tempo}

A partir de observações de processos geológicos que ocorrem no presente e o sinais que o passado geológico da Terra nos deixou, processos geológicos, unidirecionais e irreversíveis no tempo, podem ser identificados. Estes processos ocorreram no passado distante, e estão ainda ativos no presente, sugerindo que escondidos por trás deles estão leis naturais com uma direção especifica do passado para o futuro, sobre o tempo geológico profundo. Com base nestas leis, geohistoriadores são capazes de considerar o passado geológico da Terra e explica-lo por meios dos argumentos causais descritos acima. Por exemplo, apoiando-se no modelo geológico-físico, a geologia moderna pode explicar os fatores do movimento das placas tectônicas, e reconstruir a estrutura geológica da Terra no passado distante. De acordo com este modelo, fissuras ou dorsais meso-oceânicas originaram do calor e da pressão gerado no núcleo da Terra ${ }^{23}$ como um resultado da desintegração termonuclear de elementos radioativos, tais como $\mathrm{U}$, Th e ${ }^{40} \mathrm{~K}$. O calor, gerado em profundidade, se move na direção da superfície por meio de correntes de convecção.
Estas correntes, ativas na astenosfera, transportam calor em seu movimento para cima em direção à superfície, desta forma fornecendo a força motriz do movimento das placas na superfície do planeta. Neste processo a temperatura atinge mais de $4.000^{\circ} \mathrm{C}$. Como resultado, o núcleo exterior da Terra derrete e cria um fluxo de calor entre aproximadamente $3.800^{\circ} \mathrm{C}$ na base e $1.200^{\circ} \mathrm{C}$ no topo da casca. Com o decorrer do tempo, transferência de calor ocorre do topo do núcleo à base da crosta e parte do material aquecido penetra na crosta superior até os vulcões na superfície e grande parte do material sobe até o topo do manto e flui para os lados, onde resfria e sua gravidade especifica cresce gradualmente, mergulha de volta para o manto e assim por diante. No curso deste processo, a corrente de convecção sobe abaixo da dorsal meso-oceânica, se divide, e move para ambos os lados. Como um resultado deste movimento ela carrega a litosfera oceânica, usando a fricção para mover as placas para ambos os lados. Parte da corrente extrude no leito oceânico e quando a lava resfria, se transforma em basalto e aumenta a superfície do leito oceânico. Como o perímetro da Terra não muda, o crescimento do leito oceânico em um local deve ser balanceado por um decréscimo em outro lugar, ou, em outras palavras, a crosta espalhada deve se assentar em outro lugar e retornar ao manto. No outro extremo a placa oceânica é empurrada para baixo e produz uma zona de subducção caracterizada por uma fossa oceânica, arcos de ilhas vulcânicas e muitas vezes uma bacia marinha marginal, isto é, de um lado da placa um novo oceano é aberto e do outro lado um antigo oceano é fechado ${ }^{24}$. No oceano que foi aberto, entre outras, a atividade estratigráfica de rochas sedimentares tais como: rochas clásticas, biogênicas, químicas, etc. começa. A estratigrafia destas rochas sedimentares ocorre durante o tempo geológico sobre rochas básicas (ígneas) e metamórficas da crosta terrestre que são expostas na superfície do planeta.

Como pode ser visto, a explicação simplista descrita acima é baseada principalmente, conscientemente ou inconscientemente, em leis unidirecionais da física irreversíveis no tempo. A Terra, sendo um corpo quente, luta para se resfriar espontaneamente e por isto, em geral, exceto pelos processos estratigráficos de sedimentos e outros, a maioria do sistema global descrito acima é um "mecanismo" responsável pelo resfriamento continuo da Ter$\mathrm{ra}^{25}$. Olhando para estes processos e mecanismos de resfriamento e para os processos estratigráficos

\begin{tabular}{c|c|c|c|c|c}
\hline (C) Terrae Didat. & Campinas, SP & v.16 & $1-16$ & $\mathrm{e} 020007$ & 2020 \\
\hline
\end{tabular}


de rochas sedimentares, é possível identificar um número de leis geológico-físicas com uma caracterização histórica e progressiva no tempo ${ }^{26}$. Estes processos permitem aos geólogos distinguir claramente entre eventos geológicos que ocorrem no passado e aqueles que ocorrem no presente, e ligar ambos a uma causa, que sempre ocorreu no passado, enquanto o efeito ocorre no futuro, e não vice-versa. Em termos gerais, estes processos podem ser divididos em três tipos principais:

1. A produção radioativa do calor resultante da desintegração (decaimento) de materiais radioativos e a radiação emitida como resultado.

2. A atividade termodinâmica relacionada aos processos de resfriamento por meio das correntes de convecção. De fato existem três tipos de processo físico responsáveis pela transferência de calor: condução, radiação e convecção. O processo dominante no modelo geofísico, como apresentado acima, é a convecção.

3. A atividade estratigráfica de novas rochas sedimentares marinhas.

Abaixo, se segue uma descrição sumarizada desses processos:

1. Produção radioativa de calor no núcleo da Terra, originada do processo de desintegração de materiais radioativos que é assimétrica em relação à direção da seta do tempo, i.e. é um processo unidirecional e irreversível no tempo. Quando geólogos assumem uma constante de decaimento de um nuclídeo e uma taxa uniforme de decaimento radioativo, eles assumem a assimetria e não reversibilidade da seta do tempo. Nuclídeos radioativos se desintegram espontaneamente em uma taxa conhecida, de um radioisótopo pai em um nuclídeo filho. A desintegração sempre ocorre espontaneamente em uma direção, de um estado instável de um átomo para um átomo mais estável. Esta assimetria e irreversibilidade é similar, de certa forma, à assimetria da seta do tempo termodinâmica, elas compartilham da mesma direção, do passado para o futuro, e nunca ao contrário. É possível testar esta suposição olhando para a linguagem e termos profissionais utilizados por geólogos para explicar fenômenos radioativos, tais como meia-vida, idade absoluta de uma rocha, taxa de decaimento, e outros. Estes conceitos indiretamente sugerem que geólogos assumem que a seta do tempo geológica é uni- direcional; de outra maneira, estes termos não teriam significado. Se, por exemplo, geólogos assumissem que a seta do tempo é reversível, qual seria o significado do termo "meia-vida"?

2. A descrição da atividade termodinâmica, relacionada aos processos de resfriamento por meio das correntes de convecção, é baseada principalmente nas leis da termodinâmica em geral e na segunda lei da termodinâmica em particular ${ }^{27}$. Uma convenção relacionada a esta atividade diz respeito à transferência espontânea de energia da porção quente da Terra, onde a produção radioativa do calor ocorre, para a parte fria ${ }^{28} \mathrm{em}$ correspondência com a segunda lei da termodinâmica. Esta lei claramente apoia a visão de mundo evolutiva dos geólogos porque é a única lei da física que descreve o desenvolvimento progressivo de sistemas macroscópicos no tempo (Kravitz, 2013, p. 26-29). A segunda lei da termodinâmica descreve o mundo macroscópico da natureza como um mundo governado por uma seta do tempo assimétrica e irreversível - em outras palavras, descreve uma serie de eventos únicos ligados uns aos outros e desenvolvendo em uma direção (lei de sucessão histórica). Desta forma, a maioria dos fenômenos físicos, irreversíveis na dimensão do tempo, são explicados por esta lei. Na mecânica estatística, a segunda lei da termodinâmica é uma lei probabilística baseada em um conceito físico básico, a entropia. Entropia é uma medida da desordem nos sistemas físicos. A segunda lei da termodinâmica diz que em sistemas físicos fechados e isolados, a entropia pode ser mantida ou ate mesmo crescer no curso do tempo até um ponto de equilíbrio termodinâmico, que é o estado final mais provável de um ponto de vista estatístico (como um aspecto da dispersão microscópica de estados) onde o sistema pode existir (um estado de máxima entropia e desordem). A lei permite a inferência que todo sistema fisicamente fechado e isolado tem uma seta do tempo com uma clara direção, de um estado de baixa entropia (no passado) para um estado de equilíbrio termodinâmico (no futuro), onde o sistema recebe o valor mais alto que pode sustentar.

3. Um dos princípios básicos da estratigrafia é o Princípio da Superposição que foi primeiramente articulado por Nicolas Steno (1638- 
1686). O princípio pode ser formulado como segue (Kravitz, 2014, p. 692):

\footnotetext{
"Em qualquer contínuo não perturbado de estratos, qualquer estrato será mais novo do que o estrato sotoposto, e mais velho do que o estrato sobreposto. Em outras palavras, em um contínuo não perturbado de rochas sedimentares, qualquer estrato será mais novo do que aquele sobre o qual ele se encontra, e mais velho do que aquele que se encontra sobre ele, i.e., em uma coluna estratigráfica, os estratos rochosos são arranjados de acordo com a sua ordem de formação - do mais velho (na base da coluna) para o mais novo (no topo da coluna)"
}

A partir desta formulação é fácil compreender que o processo estratigráfico de uma rocha sedimentar é um processo de mão única e irreversível no tempo. Steno baseou o princípio de superposição na lei da gravidade. Ele percebeu que partículas afundam em um fluido em quantidades relativas ao seu tamanho e peso. As primeiras a afundar são as maiores, gradualmente seguidas pelas menores. Mudanças no tamanho das partículas causam a estratificação horizontal. Em outras palavras, se assumimos que a uniformidade é preservada nas leis da natureza (neste caso, na lei da gravidade), os estratos são estratificados um depois do outro, de forma que em qualquer tipo de contínuo geológico, qualquer camada deve ser mais antiga do que aquelas acima dela, e mais nova do que aquelas abaixo. De fato, ele afirma que o passado sempre precede o futuro, e que eventos futuros são casualmente influenciados por eventos passados - que a causalidade é unidirecional do passado para o futuro. As causas ocorreram no passado, e os resultados ocorrem no presente ou no futuro; desta forma, a causa deve sempre preceder o resultado. Se é assim, o processo de estratificação ocorre no curso de um longo tempo em uma direção - do passado para o futuro. Apesar de que este processo é relacionado às leis da gravidade e não à termodinâmica de processos quânticos, é também um processo físico que permite aos geólogos traçar uma ligação causal entre os eventos geológicos que ocorreram no passado e aqueles que ocorrem no presente, onde a causa é sempre mostrada no passado e o resultado aparece no futuro, e não vice-versa.

\section{Processos biológicos unidirecionais, irreversíveis no tempo}

Como descrito acima, a maioria dos processos globais geohistóricos são explicados pelos geólogos por meio de leis unidirecionais da física e da geologia, irreversíveis no tempo. Um exame dos vários aspectos da evolução mostra que essas leis afetaram e ainda afetam a geologia da Terra e indiretamente afetam o clima e o mundo animal. Humanos, como parte do mundo animal, foram, e ainda são, afetados por estas leis, não apenas no sentido biológico estrito. A teoria da evolução Neodarwiniana assume que, em princípio, existem dois mecanismos causais principais: (1) um mecanismo de variação que é um mecanismo genético causador de mudanças, seguindo mutações ou o desenvolvimento de vários vírus e outros mecanismos causais de mudança no tempo; (2) o mecanismo de seleção natural responsável pela seleção no mundo biológico, de uma forma que as criaturas sobreviventes possuem uma característica que cumpre certas condições ambientais prevalecentes na Terra, e aqueles que não sobrevivem não possuem esta característica. Isto é, em certas condições ambientais, certas características poderiam apresentar uma vantagem em comparação a outras, em termos de reprodução e transferência para a próxima geração. Tais características pode ser, por exemplo, resistência ao clima, às condições geológicas, à doença, à capacidade de utilizar certos alimentos particulares, camuflagem, etc. Condições ambientais geológicas ${ }^{29}$ representam o elemento crítico em ambos mecanismos causais, e são seguidas por mudanças no clima e em todo o mundo da flora e fauna. Uma vez que condições ambientais geológicas mudam no tempo de acordo com processos unidirecionais irreversíveis, é provável que o mecanismo de seleção natural também atue como uma causa no quadro destas leis.

Muitos exemplos do campo da biologia e da evolução da flora e da fauna fornecem suporte a esta afirmação: por exemplo, a evolução de diferentes espécies de organismos normalmente procede irreversivelmente. Este desenvolvimento pode ser dividido em três ramos biológicos avançando do passado para o futuro, que são compatíveis com a teoria da evolução de Darwin (Denbigh 1989, p. 504-505). A primeira ramificação em direção ao futuro no mundo orgânico ocorreu na Terra antiga, mesmo antes da criação da flora e da fauna. Enquanto o universo antigo esfriava gradualmente, a evolução química foi acelerada e a quantidade de 
moléculas estáveis cresceu. Este processo resultou, entre outras coisas, na proliferação de moléculas orgânicas que resultou na evolução biológica. $\mathrm{O}$ segundo ramo diz respeito ao que Darwin chamou de divergência. Desde o aparecimento inicial da vida na Terra, muitos ramos de novas espécies se desenvolveram de acordo com os mecanismos de variação e seleção natural. Durante este processo várias características se desenvolveram em criaturas com uma origem comum. Isto normalmente acontece quando diferentes forças operam nas mesmas espécies. O terceiro ramo em direção ao futuro ocorre em cada organismo individual. O desenvolvimento fisiológico de um organismo individual acontece em uma direção, irreversível no tempo, similar à direção de desenvolvimento da biosfera inteira. Por exemplo, os processos de divisão celular no corpo começam de uma célula particular e continuam na direção de múltiplas células em um organismo adulto.

O desenvolvimento evolutivo no mundo animal levou ao desenvolvimento mental de seres mais avançados, primeiramente os humanos. Processos mentais, tais como os processos biológicos descritos acima, também são, em certo sentido, unidirecionais e irreversíveis no tempo. A seguinte citação e especificação fornecem suporte a este argumento em princípio (Denbigh 1989, p. 504-505):

"Em animais superiores há também a irreversibilidade de processos mentais que, como experimentados em nós mesmos pelo menos, são a ramificação de um pensamento em outro, uma ramificação em um novo arranjo florescente e barulhento de novas crenças e intenções, novos desejos e emoções. Muitos destes itens mentais permanecem em nós como uma acumulação na memória. Percepção e cognição aparecem então com uma adição ao que já está em nossas mentes, e não como uma subtração; pois uma vez que vimos ou sabemos de algo não podemos mais sofrer o processo reverso hipotético de não ver ou não saber aquele algo. Este ponto foi ilustrado por Costa de Beauregard (1963, p. 115) que apontou o absurdo de supor que, tendo lido algum livro, nós poderíamos deletar de nossas mentes tudo o que foi dito naquele livro pelo ato de lê-lo de trás pra frente, do fim ao começo! A ramificação que ocorre na atividade mental é muitas vezes a criação de conexão - o colocar juntas as pistas para formar algum novo e significante todo na mente. Como Polanyi em particular enfatizou, uma vez que o novo todo foi apreendido suas pistas assumem um caráter diferente. Um bom exemplo é fornecido por problemas ilustrativos como aquele mostrado no Tractatus onde vemos uma cabeça de animal olhando para a esquerda, e então rapidamente percebemos que a figura também mostra uma cabeça de um animal diferente olhando para a direita. Uma vez que o duplo significado foi apreendido não podemos mais retirar o entendimento e ver a figura como representando um só animal. A cognição é irreversível”.

Do desenvolvimento cognitivo irreversível no tempo, como descrito acima, é razoável assumir que a estrutura causal-lógica do pensamento humano também foi afetada significantemente por isto. Graças a este desenvolvimento, por exemplo, podemos legitimamente nos referir ao julgamento indutivo por meio do qual nós intuitivamente implicamos o futuro do passado e não o contrário. Ainda, como vimos, qualquer explicação histórica ou geohistórica é logicamente baseada na seta causal que assume que a causa sempre precede o efeito no tempo, então permitindo aos geohistoriadores assumir leis causais do tipo "se C aconteceu então $\mathrm{E}$ aconteceu" com base em argumentos lógicos.

Se isto é correto, o que foi dito até agora pode ser sumarizado de modo mais esquemático como se segue: leis unidirecionais, irreversíveis no tempo, controlam a natureza geohistórica da Terra e deixaram sua impressão nos processos evolutivos da flora e da fauna. Como resultado, criaturas com uma mentalidade unidirecional, irreversível no tempo e capazes de implicação causal da causa para o efeito, se desenvolveram na Terra. Desta habilidade, outra foi desenvolvida, aquela de implicar a partir do efeito a causa. Em ambos os casos, compreendemos que a causa precede o efeito no tempo.

\section{Evolução, epistemologia e a relação entre elas}

A categoria de causalidade formulada por Kant, discutida neste artigo, é um dos padrões de nossas mentes que impomos sobre as impressões dos sentidos. Isto é, as leis fundamentais da natureza e o quadro básico da experiência se originam em nós. Precisamente por causa deste estado de coisas elas podem ser constantes, necessárias e universais uma vez que sensações e impressões sensoriais são fragmentais e constantemente mudam, enquanto a mente tem padrões fixos sem os quais não podemos perceber o mundo e fazer ciência. Estes são padrões gerais nos quais as impressões sensoriais entram. De fato, eles são conceitos básicos (categorias) da 
mente, que estabelecem e estabilizam a experiência e a natureza. Sem estes conceitos, não podemos explicar qualquer experiência coerente e a ciência na qual os cientistas trabalham.

De forma distinta à aproximação Kantiana, eu argumentaria que não pode haver realmente uma separação entre o mundo do conhecimento humano e o mundo da natureza, porque a mente humana, como mostrado acima, opera dentro do quadro do cérebro humano que evoluiu como parte do mundo natural (fauna natural) no curso da evolução e por meio dos mecanismos da seleção natural. Desta forma, os conceitos (categorias) da mente e as formas da percepção (espaço e tempo), só podem ser experimentais por que o processo de desenvolvimento do cérebro e da mente ao longo do tempo e pela seleção natural é experimental em todos os aspectos - qualquer coisa que sobreviva a esta experiência perdura e qualquer coisa que não sobrevive é completamente ou parcialmente extinta. É assim que um ajuste entre os conceitos de mente e de mundo exterior, que é sujeito às impressões da mente, é criado. Minha afirmação é empirista em um sentido amplo. Tanto os conceitos quanto as impressões sensoriais de nossa mente se originam no mundo experimental. O ser humano não nasce uma tabula rasa - o conhecimento experimental é acumulado no curso da evolução do cérebro e deixa uma impressão na mente. Daí a validade das leis da natureza - sob as quais a mente se desenvolveu, e é o reflexo do que acontece no mundo. Em outras palavras, as leis da natureza e as categorias são imanentemente "cauterizadas" no genoma do cérebro humano e em nossa mente. De nossa perspectiva eles aparecem a priori mas de fato os conceitos da mente são a posterior no senso amplo de aprendizado a partir da experiência da evolução. Concordo com os argumentos de Kant que graças a eles nossa experiência diária é possível, mas apenas dentro do quadro de conceitos apreendidos e sensações acumuladas de uma longa experiência de evolução.

Em outras palavras, eu argumento que ninguém pode ter conhecimento a priori mas apenas a posteriori. Qualquer conhecimento é a posteriori em um contexto e significado particular. Até mesmo as categorias e formas são "modelos" da mente construídos como funções de desenvolvimento do cérebro humano no curso da evolução. Estes "modelos" estão na verdade preservando as experiências acumuladas durante sua formação em certas condições ambientais. A lógica do pensamen- to ela mesma é uma lógica baseada em conceitos experimentais e de fato as afirmações analíticas, em sua forma e conteúdo, se originam da experiência acumulada durante a evolução humana. Em outras palavras, afirmações analíticas, ao contrário do que muitas pessoas pensam, não dependem apenas do significado das expressões que aparecem nelas.

A experiência é inerente e essas expressões por meio da evolução que as formatou durante um longo tempo e então se negamos afirmações analíticas ou argumentos dedutivos, não necessariamente recebemos uma contradição logica. Em outras palavras, estas afirmações e argumentos não são necessariamente verdade. Às vezes se a linguagem ou a lógica são substituídas, a contradição pode desaparecer. Neste sentido, eu apoio uma posição naturalística. Acredito que a humanidade é parte da natureza e que todas as leis da natureza que se aplicam a outros seres e objetos na natureza, aplicam-se a ela da mesma forma. De acordo com a teoria da evolução, a criação dos seres humanos levou bastante tempo no curso do qual a experiência foi impressa em "modelos" da mente e suas formas de percepção. Estes padrões “a priori” ("modelos") de pensamento estão crescendo durante os processos evolutivos, e como descrito acima, são afetados pelo desenvolvimento da geologia e da flora e fauna da Terra de uma forma direta e necessária. Nossa habilidade de inventar e aprender uma língua é devida à estrutura destes modelos. A lógica e as sentenças da linguagem natural foram formadas inconscientemente com base na experiência evolutiva inerente impressa nas categorias da mente e por isto nunca podem ser analíticas - a priori ou sintéticas a priori, como Kant pensava. Esta afirmação é apoiada e bem ilustrada pela seguinte citação (Campbell, 1974, p. 441):

\footnotetext{
"Apesar de rejeitarmos as afirmações de Kant de uma validade a priori para as categorias, podemos em uma perspectiva evolutiva olhar para as categorias como presunções altamente editadas, muito bem testadas, "validadas" apenas como verdades científicas são validadas - sintéticas a posteriori do ponto de vista da história das espécies, sintéticas e de muitas formas a priori (mas não em termos de validade necessária) do ponto de vista de um organismo individual”.
}

A natureza estabeleceu a experiência como absolutamente necessária e provavelmente a conexão causal também é necessária. Como descrito acima, a necessidade causal e a seta do tempo causal

\begin{tabular}{c|c|c|c|c|c}
\hline (C) Terrae Didat. & Campinas, SP & v.16 & $1-16$ & $\mathrm{e} 020007$ & 2020 \\
\hline
\end{tabular}


são produtos de processos e leis naturais unidirecionais e irreversíveis no tempo, dentro das quais e por meio das quais a mente humana evoluiu. Esta mente evoluiu de forma que se é capaz de compreender a essência da causa, imediatamente, é capaz de compreender que o efeito é o resultado de uma implicação lógica a partir dela (da causa). Assim como a soma dos ângulos é logicamente implicada da forma do polígono. A natureza determina ela mesma a necessidade de forma que a mente humana que evoluiu dentro dela e a partir dela, desenvolveu "modelos" necessários apropriados às leis da natureza que aparentemente operaram e continuam operando no curso do desenvolvimento evolutivo da mente. Nós chegamos a este mundo com estes "modelos" e expectativas inatas que habilitam o processo de aprendizagem. Estes "modelos" funcionam como instintos e algumas vezes sequer os percebemos. Por meio desta abordagem naturalística, a inferência causal é realizada como parte do funcionamento instintivo e de acordo com "modelos" inatos que foram impressos em nós de um modo natural, durante o desenvolvimento evolutivo da mente humana. Esta abordagem é apoiada por um ramo da filosofia da ciência conhecido como "epistemologia evolutiva". Esta epistemologia foi desenvolvida por Lorenz Konrad (19031989) e outros e é, em certo sentido, uma espécie de interpretação e incremento da epistemologia de Kant. Esta interpretação é conhecida na literatura filosófica como EEM (Bradie and Harms, 2015) e é de fato baseada na integração dos ensinamentos de Kant e da teoria da evolução de Darwin. De acordo com esta interpretação, conceitos a priori ou categorias, como espaço, tempo, causalidade, etc., são parte de nosso pensamento e mecanismo de percepção que é um produto da evolução biológica que ajuda um individuo a sobreviver em seu meio. A seguinte citação clarifica o assunto (Evans, 1975, p. 188-191):

"Assim como a forma do peixe é dada a priori, antes de qualquer interação do jovem peixe com a água, e assim como esta forma é o que torna possível esta interação; assim é também o caso com nossas formas de percepção e categorias em sua relação com a nossa interação com o mundo externo real por meio da experiência...

Em vez disso, todas as formas de intuição e categorias são completamente naturais. Como todo outro órgão, elas são receptáculos evolutivamente desenvolvidos para a recepção e utilização retroativa das consequências legítimas da coisa-em-si com a qual estamos lidando se quisermos permanecer vivos e preservar nossa espécie."

Baseado nesta interpretação podemos dizer que os padrões e categorias da mente são de fato "a priori" para o indivíduo que nasceu equipado com a informação genética contendo estes padrões, mas por ser um produto da evolução e da experiência do individuo em seu ambiente, ele acumula nelas toda a experiência filogenética da espécie humana e das espécies biológicas que a precederam. Neste sentido elas não são absolutas - a priori como Kant pensava. Esta abordagem argumenta, indiretamente, que existe uma possibilidade em principio de realizar uma redução entre as leis da biologia evolutiva, as leis cognitivas e as leis da logica. Recentemente esta tese de redutibilidade foi formulada mais radicalmente e diz que as leis clássicas da logica podem ser derivadas diretamente da teoria da evolução. Pode ser dito em termos de redução que a logica é redutível da teoria da evolução e a lei lógica vem diretamente da lei da evolução (Cooper, 2001, p. 2-5). Isto é, não existem leis da lógica separadas das leis da evolução. Todas as leis da lógica podem ser explicadas e descritas com conceitos do campo da biologia evolutiva. A seguinte citação clarifica e apoia esta afirmação (Cooper, 2001, p. 17):

\footnotetext{
"Que isto é possível é uma hipótese chamada aqui de Tese de Redutibilidade. Ela diz que as leis da lógica, ou ao menos da lógica clássica e certas generalizações dela, são redutíveis à biologia evolutiva em um sentido padrão: Os termos da lógica são definíveis em termos evolutivos e asserções lógicas são dedutíveis de asserções evolutivas. Se a Tese de Redutibilidade tem algum mérito, os princípios de racionalidade estão tão profundamente enraizados na teoria evolutiva que suas fundações não podem ser rigorosamente investigadas independentemente dela."
}

No presente artigo eu tento apoiar esta afirmação e estende-la ao campo da geologia. Como mencionado acima, a evolução da flora e da fauna é diretamente afetada pela evolução geológica da Terra. Desta forma, se assumimos que as categorias da mente e as leis da lógica podem ser reduzidas às leis da biologia, isto implica a possibilidade de reduzir as leis da lógica às leis da geologia. Exemplos citados neste artigo integrando as leis da lógica com as leis físicas que descrevem processos e fenômenos geológicos apoiam esta afirmação.

Hume notou duas características significativas da relação causal: a proximidade e a precedência da

\begin{tabular}{c|c|c|c|c|c}
\hline (C) Terrae Didat. & Campinas, SP & v.16 & $1-16$ & $\mathrm{e} 020007$ & 2020 \\
\hline
\end{tabular}


causa ao efeito no tempo. No presente artigo eu gostaria de enfatizar a ultima característica porque ela expressa a natureza unidirecional da cadeia causal. De outra forma, o que acontece no presente não necessariamente refletiria o que realmente aconteceu no passado. Mais especificamente, sem a causalidade unidirecional, cadeias causais que duram um longo tempo não poderiam ter sido formadas e o tempo não significaria nada e seria deixado sem uma história. Como mostrei acima, a necessidade da conexão causal provavelmente se apoia nas leis unidirecionais da natureza, como a segunda lei da termodinâmica, as leis da radiação, radioatividade, etc. Até mesmo as leis de evolução biológica são caracterizadas pela irreversibilidade unidirecional no tempo, de forma que esta foi impressa na mente humana e determinou sua estrutura.

Se isto está correto, as leis gerais da natureza expressam ligações causais gerais e justificam ligações causais especificas. Em outras palavras, podemos razoavelmente assumir que a categoria da causalidade foi derivada de leis gerais unidirecionais, por meio das quais a mente pode justificar e compreender as ligações causais específicas que encontramos na ciência e no dia a dia. A seguinte citação explica e apoia este argumento em certo sentido (Evans, 1975, p. 211):

\begin{abstract}
"Como somos hoje ignorantes de suas fundações fisiológicas, nós podemos examinar a categoria da causalidade apenas por meio da epistemologia crítica. Em sua fundação biológica, ela é um órgão para compreender a mesma legitimidade natural visada pela disposição a adquirir reflexos condicionados. Nós não podemos definir o conceito de causa e efeito de nenhum outro modo senão determinando que o efeito recebe energia da causa de alguma forma ou de outra. A essência do propter hoc que por si próprio o diferencia qualitativamente de um post hoc uniforme reside no fato de que causa e feito são ligações sucessivas na cadeia infinita de formas fenomenais que a energia assume no curso de sua permanente existência."
\end{abstract}

Formas de estruturas lógico-causais em explicações geohistóricas, como descritas no começo do artigo, justificam esta afirmação de certa forma. Nestas estruturas, a descrição de um evento deve ser obtida das leis e descrições das circunstancias em que o evento ocorreu. De acordo com este conceito, nos é permitido apoiar nos argumentos causais depois de construída uma explicação cientifica para um evento. Os eventos ou condições, descritos nas premissas da explicação, são as causas, e os eventos descritos na conclusão, os efeitos. De acordo com esta visão, a causa e o efeito são eventos ligados por uma lei com a estrutura básica "se C ocorrer então E também ocorrerá” e nela a seta do tempo causal unidirecional, irreversível no tempo, é imanentemente impressa.

Eu assumo que a causalidade de fato existe na natureza e é expressa por meio das leis da natureza. No caso da geo-história, a causalidade se origina das leis assimétricas e unidirecionais da natureza nas quais a causa sempre precede o efeito, e é expressa em explicações geohistóricas usando argumentos lógicos nos quais o primeiro argumento é a sentença lógico-causal "se C ocorre então E também ocorre". Neste sentido, como na filosofia de Leibniz, eu mantenho que as verdades de nossas mentes refletem o mundo, mas para que tal argumento possa ser utilizado, devemos assumir que a harmonia de todas as coisas com todas as coisas existe. Essa suposição pode ter uma justificativa significativa baseada na suposição que o ser humano evoluiu como uma parte integral da natureza e, portanto, quando ele decreta as leis da natureza por meio das categorias da mente e certas percepções sensoriais que são elas mesmas produtos da natureza, harmonia existe entre o ser humano e a natureza. Em um sentido epistemológico e mental, esta harmonia é expressa por meio do ajuste de todas as ideias com todas as situações objetivas expressas por elas. Aquele que é responsável por esta harmonia, segundo Leibniz, é Deus e eu estou transferindo esta responsabilidade ao processo de evolução que conecta o desenvolvimento da natureza no mundo inanimado (geológico) ao desenvolvimento da flora e da fauna (evolução), no qual emoções, mecanismos sensoriais que operam nos sentidos, sabedoria e categorias da mente evoluíram.

\section{Discussão e conclusões}

Neste artigo, eu afirmo que as origens das categorias e formas da percepção derivam da experiência evolutiva adquirida pela biologia humana com o tempo. Elas foram criadas desta experiência e desta forma podem ser aplicadas apenas a objetos suscetíveis às condições da experiência. Por exemplo, devemos assumir a lei da causalidade de forma a facilitar a transição de sensações subjetivas ao mundo objetivo. Em um aspecto lógico formal esta lei não é necessária, mas sem ela nenhuma experiência seria 
possível. Esta estrutura é possível ao assumir que as leis da causalidade arranjam eventos de acordo com a direção de seu progresso no tempo. Assumimos a priori que existe uma regra que determina a ordem objetiva de eventos no tempo. Esta regra permite que se parta da ordem das sensações para a ordem dos eventos eles mesmos. Se não assumíssemos uma regra de acordo com a qual o efeito segue a causa no mundo objetivo de eventos, não teríamos direito a interpretar a ordem subjetiva por meio de uma ordem objetiva. Como tentei demonstrar por todo o artigo, esta regra se origina nos processos evolutivos que influenciam significativamente nosso modo de pensar. O desenvolvimento evolutivo de processos geológicos e biológicos no tempo imprime a lei da causalidade na mente humana que se desenvolveu no quadro destas leis permitindo que organizemos eventos em um tempo objetivo durante o qual a humanidade se desenvolveu.

Ademais, o processo de "objetificação" 30 pelas das categorias e percepções sensoriais não se aplica apenas a objetos externos, mas a eventos mentais também (Bergmann 1972, p. 132). A consolidação de experiências mentais em uma unidade unificada é uma construção "objetificada" assim como a construção de células ou átomos na biologia ou na física. Para esta consolidação, precisamos de um pano de fundo objetivo, o pano de fundo do tempo, que utilizamos para determinar eventos mentais objetivos, assim como usamos espaço e tempo juntos para determinar objetos físicos. Neste sentido uma certa similaridade existe entre eventos emocionais e eventos que ocorrem no mundo físico e que sozinhos poderiam indicar uma unidade nas leis da natureza em que a mente humana se desenvolveu, e que não existe diferença substancial entre assumir a seta do tempo para explicar eventos mentais e assumi-la para explicar eventos físicos. Neste sentido, o pensamento constrói objetos físicos e emocionais por meio de leis que são supostamente determinadas por ele dentro das capacidades da mente ela mesma. Eu mantenho que essas capacidades evoluíram no curso da historia evolutiva da mente. Segue-se que a mente teoricamente assume o tempo a priori antes de qualquer experiência, mas na verdade o tempo existiu antes da mente e o que restou a ser desenvolvido para a mente estava no domínio da mente, e não ao contrário, como afirmado por Kant. Em outras palavras, ao contrário de Kant, minha posição é que a mente não é uma condição (pré-requisito) para a experiência, mas que a experiência é a condição (pré-requisito) para a mente. Esta é a razão porque aparentemente todo objeto físico ou psicológico é sujeito às categorias e percepções sensórias, mas a verdade é que o termo correto não é "sujeito", mas sim que existe uma correspondência entre as leis da natureza que verdadeiramente existem na nature$\mathrm{za}$ e as categorias derivadas da mente humana que evoluiu sob as mesmas leis. Desta forma podemos concluir que apenas um objeto suscetível ao pré-requisito pode possivelmente aparecer para nós. Outras possibilidades não existem para uma mente que foi desenvolvida no quadro da experiência e das leis causais que determinam a ordem objetiva dos eventos no tempo.

Se assumirmos que a coisa externa (experiência) é totalmente alheia à consciência, como então somos capazes de explicar porque ela é ainda sujeita aos seus pré-requisitos? A resposta pode ser encontrada como um resultado de nossa suposição da existência de um mundo evolutivo como descrito nos ensinamentos de Darwin. Somos criaturas que se desenvolvem em um mundo em desenvolvimento, daí a correlação entre nossa cognição e consciência e o mundo real. Desta forma o mundo externo e a experiência não são estranhos para a consciência e a cognição, porque a consciência é sujeita ao mundo externo ao invés do mundo externo à consciência, como Kant pensava. A prova transcendental de Kant revela os pré-requisitos da experiência, mas não pode responder à questão: Por que o mundo externo independente é sujeito às condições de nossa experiência? As sensações por si próprias nos oferecem o material bruto para as atividades mentais, obtidas no curso da evolução humana, o projeto da forma, permitindo compará-lo com os requisitos da mente que é ela mesmo produto desta evolução. Em outras palavras, categorias como formas de julgamento, como a percepção sensorial, são funções fisiológicas do cérebro e isto, talvez, explique a sua validade lógica a priori. Espaço, tempo e causalidade são pré-preparados em nossas mentes assim como a visão é pré-preparada em nosso nervo óptico. A validade a priori destas formas de julgamento e percepções sensoriais é devida à nossa habilidade inerente em um sentido fisiológico-evolutivo. Se isto está correto, ajustar o mundo à mente é meramente ajustar a mente ao mundo que é criação da natureza. O mundo é translúcido e compreensível aos humanos, porque o ser humano ele mesmo é apenas a essência do mundo, contendo todos os elementos que fazem parte do mundo em seu ser. Essa consciência e percepção da mente são uma 
criação do cérebro humano, que é ele mesmo uma criação da natureza. Categorias de nossas mentes e percepções sensoriais são na verdade funções criadas para a sobrevivência, formadas por meio da experiência evolutiva e escolhidas durante a luta pela existência, porque elas foram as mais adaptadas à realidade. Em outras palavras, a raça humana adquiriu as categorias e percepções sensoriais por adaptação à realidade. Estas foram as ferramentas que se ajustaram ao mundo e às suas leis e desta forma elas foram preservadas e herdadas, enquanto outras ferramentas mentais que não se ajustam à realidade do mundo foram destruídas e perdidas (Bergmann 1972, p. 181).

O objetivo deste artigo foi mostrar, por meio de explicações, com base em suposições fundamentais e observações cientificas dos campos da geologia e da biologia, como é possível argumentar que a mente humana e suas ferramentas lógicas foram originadas dos processos da natureza e não necessariamente estabelecidas por essas leis, mas ao invés disto foram adaptadas ao ambiente em que se desenvolveram por meio de milhares de anos de evolução. Esta afirmação, se justificada, pode apoiar a afirmação que a natureza, em geral, e a natureza humana, em particular, implicam que, em princípio, há uma possibilidade de derivar a seta causal do tempo de um número de setas físicas do tempo que existem na natureza, e aparecem para nós como fenômenos unidirecionais e irreversíveis. É claro que uma afirmação reducionista como essas necessita de muitas outras justificativas que eu deixo para futura pesquisa.

\section{Notas}

${ }^{1}$ Para uma discussão mais profunda do desenvolvimento histórico desta abordagem, ver Romano (2015).

${ }^{2}$ Para uma discussão mais profunda do desenvolvimento histórico deste princípio, ver Romano (2015).

${ }^{3}$ É crucial apontar aqui que o principio de uniformidade é aplicado para fornecer necessidade logica à inferências ao passado. Porém, esta necessidade na explicação é um assunto para reconstruções racionais realizadas por filósofos. Em trabalhos práticos os geólogos estão bem mais interessados na fecundidade das suas explicações propostas (hipóteses) do que em sua necessidade lógica.
${ }^{4}$ Deve ser notado que não é exatamente assim que os geólogos usam a analogia na prática. Na prática o uso da analogia combina premissas indutivas ilustradas por uma inferência abdutiva que forma uma hipótese causal. Para mais detalhes sobre esta inferência, ver Kravitz (2013).

${ }^{5}$ Sobre as diferenças metodológicas e epistêmicas entre ciência histórica e ciência experimental, ver Cleland (2002).

${ }^{6}$ Sobre o papel do raciocínio analógico na geologia, ver Baker (2014).

${ }^{7}$ Para uma discussão mais profunda sobre metodologias de inferências geohistóricas e em ciências planetárias, ver: Peirce $(1867,1883)$, Chamberlin (1890, 1904, 1897), Gilbert (1896), Engelhard and Zimmermann (1988) e Baker (2014). Porém, deve ser lembrado que inferências analógicas não são nada mais que inferências indutivas, e neste sentido não são logicamente válidas em um sentido dedutivo.

${ }^{8}$ A circularidade da causalidade já era conhecida por filósofos céticos na Grécia Antiga. Sobre esta circularidade veja, por exemplo: Barnes (1990, p. 58-89).

${ }^{9}$ Sobre este processo, veja, por exemplo, Peirce (1867, 1883), Chamberlin (1890, 1904, 1897), Gilbert (1896), Kitts (1977), Baker (2014), Kravitz (2012, 2013) e Cleland (2013). Deve ser enfatizado que o que eu digo aqui não é exclusivo para a geologia. Em todas as observações cientificas podemos observar o efeito, mas a causa é sempre uma melhor hipótese que podemos testar. A grande diferença é que na geologia é difícil replicar as condições necessárias para testar as hipóteses causais e ademais os geólogos tendem a eliminar múltiplas hipóteses durante os trabalhos de campo, ao menos de acordo com os trabalhos clássicos sobre filosofia da geologia.

${ }^{10}$ Aqui estou me referindo ao famoso problema de indução levantado por David Hume. Sobre este assunto, ver: Bonjour (2009, p. 47-69), Feldman (2003, p. 130-141).

${ }^{11}$ Usando o princípio de uniformidade os geólogos, de fato, estão tentando transformar as sentenças condicionais "se C ocorreu então E ocorreu" em uma sentença condicional essencial que diz que o evento C é uma condição essencial para o evento E. Em outras palavras, eles tentam transformar o padrão da sentença para padrões do tipo "o evento 
E ocorreu apenas se o evento C ocorreu" ou "se o evento $\mathrm{C}$ e apenas o evento C ocorreu então o evento E ocorreu". Nestas sentenças se o evento $\mathrm{C}$ ocorreu então necessariamente o evento $\mathrm{E}$ ocorreu, mas o caso inverso não necessariamente existe (em sentenças condicionais normais a primeira seção é uma condição suficiente para a seção final e a seção final é uma condição necessária para a primeira seção). Para maiores detalhes, ver: Kravitz (2013, p. 29-32). Eu irei aqui clarificar alguns destes conceitos, como "condição suficiente" e "condição necessária". Condição Suficiente - o evento H é uma condição suficiente para a ocorrência do evento I se, e somente se quando o evento H ocorre, o evento I ocorre também, i.e., é suficiente que H ocorra para que I ocorra. Condição Necessária - o evento Hé uma condição necessária para a ocorrência do evento I se, e somente se, sem a ocorrência do evento $\mathrm{H}$ o evento I não pode ocorrer, i.e., se H não ocorre, I também não pode ocorrer.

12 Esta afirmação é verdade para argumentos analógicos que vão ou da causa para o efeito ou do efeito para a causa. Sobre o realismo em relação à geologia do passado, ver: Kravitz (2013, p. 20-22), Kravitz (2012, p. 9-23).

${ }^{13}$ Em lógica estamos lidando com inferências dedutivas e não com explicações causais. Inferências são algo na mente (intelecto) e causas são algo no mundo físico (mecânico). Quando falamos sobre justificação estamos falando sobre inferências e não sobre causas físicas.

14 Sobre o uso de uma variedade de argumentos lógico-causais, ver: Engelhardt e Zimmermann (1988, p. 139-233).

15 Neste sentido este fato por si próprio pode indicar a fé realística dos geólogos sobre nossa habilidade de conhecer o mundo físico ao nosso redor, por meio dos julgamentos e da razão da mente humana (ou na linguagem de Kant que iremos discutir mais à frente, usando categorias ou puras intuições).

${ }^{16}$ É válido mencionar aqui que nem toda explicação histórica é uma explicação baseada na causalidade e portanto inferências lógico-causais nem sempre são necessárias. Explicações históricas podem ser explicações intencionais que lidam com os motivos das pessoas e outros estados de consciência. Essas explicações não requerem leis ou legalidade causal (a causalidade é descritiva, não judicativa); elas são essencialmente explicações normativas (julgamentos éticos: melhor, mais certo, etc.) em um sentido específico e não são lógicas. Em contraste a estas, em geo-história muitas vezes lidamos com as causas e leis porque explicações geohistóricas são baseadas nas leis da física e descritas por eventos históricos. Porém, em alguns casos em geo-história, também lidamos com explicações descritivas de uma dada narrativa geohistórica. Sobre explicações descritivas, veja a nota 109 em Kravitz (2013, p. 38).

${ }^{17}$ Durante o seu trabalho diário os geólogos são confrontados com uma multidão de problemas práticos que concernem à causalidade geológica. Por exemplo, eles muitas vezes afirmam que a mesma causa pode resultar em diferentes efeitos (divergência) ou que varias causas poderiam produzir o mesmo efeito (convergência). Ademais, eles afirmam que certo efeito é as vezes resultado de uma combinação de várias causas (multiplicidade). Sobre problemas práticos que dizem respeito à causalidade geológica, ver Schumm (1998, p. 58-75, 95-119) e Cleland (2013, p. 4-7).

${ }^{18}$ A origem da distinção entre analítico e sintético está em Kant. Para facilitar ao invés de confundir o leitor sobre as observações precisas de Kant, eu simplifiquei e clarifiquei estes conceitos o máximo possível. Por falta de espaço, estes conceitos não serão discutidos além do que foi dito aqui. Para uma discussão mais detalhada destes conceitos, ver: Yovel (2013, p. 35-39).

${ }^{19}$ Como expliquei acima, na lógica clássica, sentenças condicionais dizem algo sobre uma relação existente entre a primeira seção e a seção final. Elas podem representar diferentes tipos, como sentenças onde a seção final é logicamente implicada da primeira seção ou de definições de conceitos contidos na sentença, e por aí vai. A geologia e outras ciências naturais muitas vezes usam sentenças condicionais onde a conexão entre as seções inicial e final é uma relação empírico-causal. Em todo caso, é importante entender que logicamente, a característica lógica comum a todas as sentenças condicionais é que se a primeira seção é verdade e a seção final é falsa então a sentença condicional é falsa.

${ }^{20} \mathrm{Na}$ linguagem de Kant pode ser dito que estas sentenças representam a categoria da mente humana "causa e efeito" (causalidade e efeitos) 
que é expressa numa forma lógica (forma intelectual) sob a seção "relação" e forma de julgamento (ou forma de sentença "hipotética"). Sobre estes conceitos ver: Yovel (2013, p. 50, 169-175). Para maiores detalhes sobre as suposições metafisicas da causalidade, ver: Kravitz (2013, p. 31-32).

${ }^{21}$ Modelo de explicação de acordo com o qual para explicar um evento em referencia à outro evento necessariamente se pressupõe um apelo às leis ou proposições gerais que correlacionam eventos do tipo a ser explicado com eventos do tipo citado como suas causas ou condições. Para detalhes mais profundos, ver Hempel and Oppenheim (1948).

22 Sobre reducionismo na geologia, ver: Kravitz (2013, p. 33-38).

${ }^{23}$ Como hoje é reconhecido, a maioria do calor dentro da Terra vem do decaimento de materiais radioativos. Porém, existem, ou existiram um dia, fontes de calor adicionais causadas pela gravidade da Terra (especialmente nos estágios iniciais de formação da Terra), forças de maré (quando a Lua estava mais próxima da Terra), a fricção gerada pelo movimento das placas e o calor irradiado durante a cristalização do núcleo (Poirier, 2000, p. 230-231).

${ }^{24}$ Para maiores detalhes, ver por exemplo Stewart (1990, p. 72-123).

${ }^{25}$ Este é o próprio processo de resfriamento. Isto não significa que a Terra efetivamente esfria. Apesar do decaimento radioativo ser a principal fonte de calor, podem haver outras fontes ainda não conhecidas e desta forma o assunto ainda levanta controvérsias e debate entre os geólogos (Poirier, 2000, p. 230). Se assumirmos que a única fonte de calor é a desintegração de materiais radioativos, é claro que hoje a Terra está em processo de resfriamento. A maioria dos geólogos acredita que uma redução permanente da reserva de energia da Terra existe como um resultado da amortização de materiais radioativos (que estão sofrendo decaimento). Por exemplo, nós hoje sabemos que a energia associada com a desintegração de material radioativo na Terra é 5,5 vezes menor que a energia que a Terra tinha 5 bilhões de anos atrás.

${ }^{26}$ É claro que existem outros processos físicos e químicos (reversíveis e irreversíveis no tempo) que participam no processo global descrito aqui, mas uma vez que o artigo é filosófico, eu não pretendo entrar em detalhes nestes processos. De um lado os processos listados acima são centrais no processo global e de outro lado é relativamente fácil para o leitor médio que não é proficiente em disciplinas investigativas praticadas em diversas ciências da Terra compreender.

${ }^{27}$ Aqui a explicação para os processos termodinâmicos será geral e qualitativa, mas suficiente para os propósitos deste artigo. Para uma explicação detalhada e quantitativa, ver: Poirier (2000, p. 230-244).

${ }^{28}$ Como descrito acima, em geral, existem três tipos de mecanismo responsáveis pela transferência de calor: condução, radiação e convecção. O mecanismo mais importante no modelo geológico-físico é a convecção, então irei colocar especial ênfase nele. Para o resto dos mecanismos de transferência de calor, ver Turcotte and Shubert (2002, p. 132-194, 262-292).

${ }^{29}$ Aqui estou me referindo a fontes mutagênicas de variabilidade que tem um impacto profundo na taxa de desenvolvimento de mutações.

${ }^{30} \mathrm{O}$ processo de objetificação é a operação de construir um objeto constante e unificado a partir de uma multiplicidade de sensações. Ele conecta diferente emoções em uma conexão permanente e mantem a conexão criada desta forma apesar das mudanças nos sentimentos, e das mudanças que ocorrem nas coisas elas mesmas. Neste processo o objeto está sendo criado em nossas mentes a partir da conexão de muitas impressões. Para isolar um objeto e mante-lo em sua identidade nesta proliferação, precisamos atravessar uma multiplicidade de sensações, juntá-las e realça-las como uma unidade singular na frente de outras impressões do ambiente. Para maiores detalhes, ver: Bergmann (1972, p. 119-145).

\section{Referências}

Baker, V. R. (2014). Terrestrial analogs, planetary geology, and the nature of geological reasoning. Planetary and Space Science 95, 5-10. doi: 10.1016/j. pss.2012.10.008.

Barnes, J. (1990). The Toils of Scepticism. Cambridge University Press, Cambridge, $161 \mathrm{p}$.

Bergmann, S. H. (1972). Introduction to the Theory of Knowledge. The Hebrew University Magnes Press, Jerusalem. 318p.

Bonjour, L. (2009). Epistemology: Classic Problems and 
Contemporary Responses. Rowman \& Littlefield Publishers, Inc., Lanham, Maryland. 331p.

Bradie, M., Harms, W. (2015). Evolutionary epistemology. In Zalta, E. N. (Ed.). (2015). Stanford Encyclopedia of Philosophy. http://plato.stanford.edu/ archives/sum2015/entries/epistemology-evolutionary/. (Summer 2015 Ed.).

Campbell, D. T. (1974). Evolutionary epistemology. In: Paularthur, S. (Ed.). (1974). The Philosophy of Karl Popper. The Library of Living Philosophers, Inc., USA, pp. 413-463.

Chamberlin, T. C. (1890). The method of multiple working hypotheses. Science, 15, 92-96.

Chamberlin, T. C. (1897). The nature of multiple working hypotheses. The Journal of Geology, 5, 837848. doi: 10.1086/607980.

Chamberlin, T. C. (1904). The methods of Earth-Sciences. Popular Science Monthly, 66, 66-75.

Cleland, C. E. (2002). Methodological and epistemic differences between historical science and experimental science. Philosophy of Science 69 (3), 474-496.

Cleland, C. E. (2013). Common cause explanation and the search for a smoking gun. In: Baker, V. R. (Ed.). (2013). Rethinking the Fabric of Geology. Geological Society of America, Special Paper 502, pp. 1-9. doi: 10.1130/2013.2502(01).

Cooper, W. S. (2001). The Evolution of Reason: Logic as a Branch of Biology. Cambridge University Press, Cambridge, UK. 226p.

de Beauregard, O. C. (1963). Le second principe de la science du temps. Paris, Editions du Seuil.

Denbigh, K. G. (1989). The many faces of irreversibility. The British Journal for the Philosophy of Science, 40, 501-518.

Engelhardt, W., Zimmermann, J. (1988). Theory of Earth Science. Cambridge, UK, Cambridge University Press. 400p.

Evans, R. (1975). Konrad Lorenz: The Man His Ideas. New York, Harcourt Brace Jovanovich. 301p.

Feldman, R. (2003). Epistemology. New Jersey: Pearson Educ., Inc. 197p.

Gilbert, G.K. (1896). The origin of hypotheses. Science 3, 1-12.

Hempel, C., Oppenheim, P. (1948). Studies in the log- ic of explanation. Philosophy of Science 15, 135-175 (Reprinted in Hempel, 245-290, 1965a).

Kitts, D. B. (1977). The Structure of Geology. Dallas, SMU Press. 199p.

Kenaz, Y. (2010). Descartes, a Discourse on the Method (in Hebrew). The Books in the Attic Press, Tel-Aviv, Israel, $123 \mathrm{p}$.

Kravitz, G. (2012). Basic Assumptions of Geo-historical Thinking [Ph.D. dissertation].University of Haifa, Department of Philosophy, Haifa, Israel, 255 p (in Hebrew).

Kravitz, G. (2013). The thermodynamics time arrow and the logical function of the uniformity principle in geohistorical explanation. In: Baker, V.R. (Ed.), Rethinking the Fabric of Geology. Geological Society of America, Special Paper 502, pp. 19-40. doi: 10.1130/2013.2502(03).

Kravitz, G. (2014). The geohistorical time arrow: from Steno's stratigraphic principles to Boltzmann's past hypothesis. Journal of Geoscience Education 62, 691-700.

Peirce, C. S. (1867). On the natural classification of arguments. Proceedings of the American Academy of Arts and Sciences 7, 261-287.

Peirce, C. S. (1883). A theory of probable inference. In: Peirce, C.S. (Ed.), The Johns Hopkins Studies in Logic. Little and Brown and Co, Boston, pp. 126-181.

Poirier, J. P. (2000). Introduction to the Physics of the Earth's Interior. Cambridge, Cambridge University Press. $312 \mathrm{p}$.

Romano, M. (2015). Reviewing the term uniformitarianism in modern Earth Sciences. Earth Science Reviews, $148,65-76$.

Schumm, S. A. (1998). To Interpret the Earth: Ten Ways to Be Wrong. Cambridge University Press, Cambridge. $144 \mathrm{p}$.

Stewart, J. A. (1990). Drifting Continents \& Colliding Paradigms. Indiana University Press, USA. 285p.

Turcotte, D. L., Schubert, G. (2002). Geodynamics. New York, Cambridge University Press. 456p.

Yovel, Y. (2013). Immanuel Kant-critique of Pure Reason. Hakibbutz Hameuchad-Sifriat Poalim, Tel-Aviv. 654p. (in Hebrew, Translated with Introduction and Notes by Yirmiyahu Yovel). 